\title{
Mihaela Munteanu Siserman, Nume și simțuri: corespondențe semantice în configurații denominative, Editura Mega, Editura Argonaut, Cluj-Napoca, 2015, 260 p.
}

\author{
Daiana Felecan* \\ Facultatea de Litere, Universitatea Tehnică din Cluj-Napoca, Centrul Universitar Nord, Str. Victoriei 76, 430122 Baia Mare, România
}

Provocator încă din paratext, volumul Mihaelei Munteanu Siserman, Nume și simțuri: corespondențe semantice în configurații denominative (Editura Mega, Editura Argonaut, Cluj-Napoca, 2015, 260 p.), adună laolaltă, așa cum aflăm din Introducere, contribuțiile-adăugite şi actualizate din punctul de vedere al bibliografiei-publicate de autoare în ultimii ani, a căror temă comună de cercetare este știința numelor. Cartea reunește, sub egida unei onomastici integratoare, studii care urmăresc capacitatea numelui propriu de a contracta diverși determinanți, cazuri de „deonomasticizare” (prin antonomază), în ambele demersuri autoarea apelînd la metodologii de factură morfo- și lexico-semantică.

Se poate vorbi, pe drept cuvînt, despre o retorică a titlurilor de capitole din cartea recenzată, efectele de sens fiind înregistrate încă de la această situare textuală preliminară (avertisment / anticipativă).

În spiritul onestităţii cercetătorului consacrat, colega noastră oferă, după titlul fiecăruia dintre cele 11 studii ale cărții, referința bibliografică inițială exactă sau numele manifestării științifice în cadrul căreia a fost susținută comunicarea.

Certitudinea noastră, la parcurgerea primului dintre studii (din cea dintîi secțiune a cărții: Nume proprii vs nume comune), Despre cîteva clase lexicosemantice de nume proprii devenite nume comune (p. 22-40), este că avem a face cu o enciclopedie „de buzunar” (caracterul „dozat” al informației fiind explicabil prin delimitarea de către autoare a cîmpului de interes, îngrădire intrinsecă, de altfel, oricărei teme de cercetare). Două preocupări au stat în atenția colegei noastre, și anume i) să inventarieze și să expliciteze cei mai cunoscuți / vehiculați termeni comuni care ,incapsulează” în structura lor lexicosemantică un nume propriu și ii) să redea succint istoria referentului (antroponim sau toponim) originar, marcîndu-i, totodată, periplul (extra)lingvistic al lexicalizării („deonomasticizarea”). În temeiul afirmației de mai sus, colocația din titlu „nume comun” în succesiunea celei de „nume propriu” este justificată, deși repertorierile din text redau deonimizate. Autoarea distribuie în părți grafice echilibrate comentariile referitoare la ambele categorii de nume (comune vs proprii) investigate.

Sectoarele de incidență ale „urmelor” propriale din eponimele considerate sint: cel al vieții cotidiene (dintre ale cărei domenii sînt explorate lexico-semantic cel gastronomic, al îmbrăcămintei și al accesorizării, al divertismentului), cel tehnicoștiințific, al faunei, florei, mitologiei, religiosului și al așa-numitelor curiozități onomastice.

Strategia inversă la care autoarea face apel în abordare, prin eponim la sursă (sursa fiind luată în discuţie cu calitatea de criteriu taxonomic), permite o mai clară observare de către cititor a modalităţii polifonice de construire a unităților nominale investigate; acesta este provocat să acceseze (să actualizeze / să asimileze) un halou de informații conexe (cotext enciclopedic), „alăturări” lexicografice și de cultură universală, care să-l salveze de poziționarea pe o eventuală pistă interpretativă (de decodare) eronată. [A se vedea, de exemplu, dezlegarea originii sintagmei bişon maltez (p. 31)].

„Închiderea” unui nume propriu (antroponim sau toponim) într-unul comun-procedeu frecvent în limbile istorice-, conchide autoarea, se reflectă în legătura onomastică existentă între numele „comunizat" și sorgintea lui proprială [antroponimele care se întrezăresc în structura de adîncime a eponimului trimit la numele unui referent ilustru, după cum toponimele au „amprentat” incidența locativă a produsului / calităţii denumit(e)].

Drept o analiză ce se revendică mai cu seamă din perspectiva logicii lingvistice se constituie cel deal doilea studiu din cartea de faţă, Comportament

\footnotetext{
*Adresă de corespondență: daiana18felecan@yahoo.com.
} 
morfosintactic și funcție discursivă în cazul numelor proprii cu / färă determinanți (p. 41-66). Făcînd dovada unei foarte bune cunoașteri a teoriilor privitoare la statutul semantico-referențial al numelui propriu (pe linia Kripke, Milner, Mill, Kleiber), Mihaela Munteanu Siserman întreprinde o minuțioasă analiză a valorilor acestuia (date fie de calitatea sa denominativă, fie de intenția locutivă) în contexte de utilizare cu / fără determinanți. Autoarea identifică o serie de funcții discursive ale numelui propriu ca parte a unor sintagme nominale, urmărind gradul de „fidelitate” al numelui referentului discursiv în ce privește reiterarea numelui referentului inițial.

Din cadrul capitolului dedicat numelui propriu fără determinanți (p. 43-47), reținem depăşirea de către autoare a limitelor interpretării de la nivelul text-discursului, în spatele precizărilor de proveniență gramaticală trădîndu-se predilecția cercetătoarei pentru faptul de limbă exploatat pînă la ultima potenţă morfologică și lexicografică. Observații utile găsim în analiza sintagmelor alcătuite din apelativ + nume propriu. Despre primul component al formulei denominative se afirmă că are capacitatea de a conferi o putere individualizatoare suplimentară celei intrinseci numelui propriu, indicînd relaționarea stabilită între titularul acestuia și locutor. Prin urmare, părțile binomului nominal au rost clarificator al referinței, contribuind reciproc la „elucidarea” denotatului.

Determinanții (adj. dem., art. hot. / nehot., adj. pos. sau nume propriu extins) din structura unei sintagme nominale propriale (p. 47-56) fie ajută la fixarea referinței, fie inserează o discontinuitate în lanțul denominativ nume propriu - referent, cu consecințe (semantico-stilistice) la nivelul textului. Numele proprii „dezincarnate” (Gardiner) din pricina ocurenței unui art. nehot., de exemplu, fixează referentul la nivelul predicației și nu prin relația nume propriu - referent, numele propriu pierzîndu-şi (într-un atare statut nedefinit) „valoarea referențială care i-ar permite identificarea referentului” (p. 48). Prezența demonstrativelor, rezultă din analiza contextuală, poate actualiza următoarele roluri: focalizator în ceea ce privește referentul, continuator tematic sau, dimpotrivă, demarcator discursiv.

Un loc aparte rezervă autoarea „numelor proprii ilustre (cu sau fără determinanți), care conduc la ruperea legăturii denominative” (p. 53-56). Este vorba despre utilizările exemplare, metaforice și metonimice, în interiorul cărora „modificarea referinței iniţiale vizează, în planul discursului, invocarea unui alt referent, virtual sau real, cu care se stabilesc anumite legături pe baza unor tradiții lingvistice și culturale” sau „prin trimitere directă la referentul inițial” (p. 62).

Numele proprii cu determinare posesivă (p. 5262) contribuie la „citirea” corectă a referentului textual, producînd diverse efecte pragmastilistice: de distanțare, de familiaritate față de referentul expresiei posesive, precizînd, în orice caz, "gradul de autonomie a obiectului posedat faţă de posesor" (p. 63).

Alegerea titlului celei de-a doua secțiuni a cărții, Onomastică senzorială, este motivată de autoare în sensul corespondențelor instituite între diferitele niveluri de cunoaștere (olfactivă, gustativă, vizuală şi tactilă) a numelui. Prin analiza numelor de parfumuri, a celor de produse culinare, de emisiuni de televiziune, de monede, de maladii / virusuri şi a supranumelor de domnitori, Mihaela Munteanu Siserman întărește convingerea necesității amplasării prioritare a actului atribuirii de nume între celelalte activităţi psiholingvistice.

În cadrul onomasticii senzorialului olfactiv, Mihaela Munteanu Siserman investighează, dintr-o perspectivă semiolingvistică, numele de parfumuri (Nume proprii de parfumuri: o analiză semiolingvistică, p. 68-85). Potrivit autoarei, numele propriu poate fi analizat într-o triplă dimensiune: semiotică („structurile lingvistice în funcție de care și prin care acest obiect este identificat”, p. 65), pragmatică (drept produs al unui comerciant pentru potențialul client), socioculturală (efortul cognitiv al beneficiaruluicare face trimiteri extralingvistice-pentru descifrarea numelui propriu). Din perspectiva considerării numelui propriu ca semn, sînt identificate următoarele categorii de nume proprii (cu subcategoriile aferente): nume proprii care dețin o componentă lingvistică generică; nume proprii ce redau, sub diverse modalităţi-transparent sau prin apel la procedee lingvistico-stilistice-, numele creatorului / al producătorului / al casei de parfumuri. Din perspectivă pragmatică, se are în vedere destinatarul căruia i se adresează produsul respectiv. Acesta este menţionat explicit sau este posibil a fi reconstituit prin mijloace inferențiale. (Autoarea observă, de exemplu, că în numele proprii pentru femei din 
corpusul prelucrat nu există, cu o singură excepție, vreun indiciu lexico-semantic orientativ întru recuperarea destinatarului feminin, acesta fiind reperabil prin opoziție cu numele parfumului conceput pentru bărbați). Considerat de omul modern o anexă a personalității, parfumul îndeplinește și o funcție socială, prin „asortarea” lui cu diversele evenimente din viața individuală. Astfel, în clasificarea autoarei, găsim nume proprii circadiene; nume proprii cu referire la variile domenii ale socialului (sport, agrement etc.); nume proprii sinestezice; nume proprii ce reiterează denumirile celor patru elemente primordiale (apă, aer, pămînt, foc); nume proprii ce redau un toponim (locul de fabricație / de comercializare a parfumului); numele proprii ,încărcate” enciclopedic implică un parcurs inferențial (cultural, istoric, social etc.) întru decriptarea corectă semantic; nume proprii care trimit la personaje și personalități exemplare; nume proprii cu rezolvare intertextuală; nume proprii descriptive (unele reproducînd scheme argumentative, toate conţinînd ,închise în structura lor profundă, nerostită, o poveste trăită sau dorită ori planificată” (p. 80); nume proprii-număr (cifră) (opțiune explicabilă fie prin înscrierea produsului intr-un lanț numeric, fie prin valoarea subiectivafectivă „încifrată” în nume de către parfumier).

Majoritatea numelor proprii repertoriate sînt motivate obiectiv sau subiectiv-afirmă pe bună dreptate autoarea-, cheia lecturii corecte nereducîndu-se la cea literală, ci la una evocatoare de cunoștințe de diverse ordini, provenite dintr-un context lărgit (extralingvistic).

La baza alegerii unei atare teme de cercetare-ne referim la Onomastica senzorialului gustativ. Nume de preparate culinare autohtone in perspectiva globalizării (interpretări onomastice și socioculturale) (p. 86-113) - trebuie să fi stat-deducem din afirmația autoarei-constatarea bogăției și a varietății de gusturi, forme, arome și culori rezultate din ingredientele și mîncărurile (de)săvîrşite deopotrivă în bucătăria autohtonă și în cea universală.

Trecînd prin diversele faze de contact intercultural ale terminologiei culinare românești surprinse în diacronie, Mihaela Munteanu Siserman întreprinde o tipologizare a acesteia i) din perspectiva ocurenței unui lexem onomastic în structurile inventariate, ii) în privința componentei lexico-semantice și iii) la nivelul stabilirii etimonului. Corpusul consultat provine din surse de notorietate în virtutea vechimii și rulajului excesiv (cărți de bucate), dar și din cel întocmit de autoare (prin extragerea unităţilor de analiză din internet sau prin consemnarea directă a numelor de produse din spațiile comerciale corespunzătoare).

Găsim formulată o definiție a gastronimelortermen-umbrelă, sub care sînt reunite numele produselor din gastronomia românească: „,...] denumiri atribuite unor feluri de mîncăruri / produse culinare şi băuturi, inventariate în cărțile de specialitate sau pe site-urile din internet consacrate gastronomiei, dintr-o perspectivă onomasiologică şi / sau semasiologică, adică pe secțiuni care repertoriază rețete culinare în funcție de «cronologizarea» etapelor în «ritualul» mesei sau taxonomii ale diferitelor clase gastronomice" (p. 89-90).

Componenta specifică (onomastică) din structura lingvistică a gastronimelor-căci în funcție de aceasta $s$-a făcut taxonomia diferitelor (sub)claseare o alcătuire lexico-semantică explicită sau implicită, trimițind, în consecință, direct sau indirect, la antroponimul sau toponimul inclus în semnifica(n)t.

Antroponimele identificate in structura gastronimelor sînt nume de familie și nume proprii ilustre, a căror prezență este explicabilă prin actualizarea unui anumit context gastronomic.

Gastronimele care conțin toponime sînt repartizate gramatical conform următoarelor tipare sintactice: 1. apelativ (componenta generică) $+/$ - prep. + Determinant nume propriu și 2. apelativ + adj. relațional toponimizat.

O altă clasificare (lexico-semantică) ordonează gastronimele în: detoponime și deantroponime; originea lor funcționează, de asemenea, drept criteriu clasificator. Analiza continuă pînă la detaliu, gastronimele fiind ordonate, la nivel stilistico-pragmatic, în: gastronime metaforice, gastronime pragmatice (în interiorul acestei grupe întîlnim gastronime ,anticriză”, pe care autoarea le pune în legătură cu „efectele negative ale societăților de consum”, p. 109, generatoare de crize financiare și temporale) și (alte) categorii semantice de gastronime.

Ca observație generală, Mihaela Munteanu Siserman notează tendința de occidentalizare a corpusului onomastic din nomenclatorul gastronomiei românești actuale: „«Spune-mi ce mănînci ca să-ți spun cine ești» pare să-și fi pierdut referințele identitare într-o eră globalizantă și globalizatoare, denumirile autohtone ale produselor culinare reprezentînd o 
ultimă redută în fața asaltului bucătăriei de tip fastfood, cu consecințe atît asupra mentalităților, cît și a comportamentului culinar" (p. 110).

Preocuparea autoarei pentru denumirile din domeniul culinar-gastronomic se continuă în studiul Influența limbii franceze asupra numelor culinare româneşti (p. 114-130), de data aceasta scopul find realizarea unei schițe lexicologice / lexicografice a influenței exercitate de limba franceză asupra vocabularului românesc menționat.

În evaluarea semantică a faptelor de limbă, Mihaela Munteanu Siserman distribuie materialul în funcție de izotopiile subsumate următoarelor categorii: nume de deserturi, produse de patiserie și cofetărie; nume de sosuri; nume de tipuri de cărnuri; nume de ustensile folosite la bucătărie.

Autoarea constată că unii termeni au suferit în limba împrumutătoare modificarea sensului deținut în limba de origine [fie prin extrapolare, fie prin convertire semantică și / sau a formei (ca urmare a tendinței de adaptare la cerințele foneticomorfologice ale românei)]. Alții și-au conservat „fizionomia” originară. În general, numele culinare românești provenite din franceză se păstrează, chiar dacă de-a lungul timpului au survenit diverse metamorfoze, explicabile prin contactul cu alte etnocivilizații gastronomice, prin schimbarea mentalităţilor și prin transformările din planul vieții social-politice și culturale.

Invocînd tradiţia viticolă românească îndelungată (recunoașterea supremației Traciei între celelalte regiuni ale Europei în ce privește calitatea vinurilor produse aici), Mihaela Munteanu Siserman dedică un articol din cuprinsul lucrării sale numelor de vinuri şi de soiuri de struguri româneşti (p. 131150). Perspectiva de analiză este una lingvisticostructurală şi semantico-pragmatică [urmărindu-se, cu precădere, relația instituită între producător (prezent la nivelul etichetajului nominal) și beneficiar (cumpărător / consumator)].

În marea lor majoritate expresii designative motivate, structurile nominale identificate au fost distribuite în mai multe categorii semantice, după cum urmează: nume care trimit la etnonimul țării de proveniență (uneori, structura conține un hidronim, oronim etc.): Tămîioasă românească, Dunărea Albastră; denumiri care conțin apelative ce trimit spre sensul de „moștenire”: Hereditas, Tezaur, Zestrea; denumiri care conțin toponime ale originii: Jidvei,
Murfatlar, Tîrnave etc.-cu următoarele subcategorii: termenul generic domeniu (sg. / pl.) + toponim: Domeniile Segarcea; termenul moşie + toponim: Moșia de la Tohani; nume de forme de relief + Determinant: Dealu Mare; locative: Beciul Domnesc (cu subcategoria casa / familia + antroponim identificator: Casa Isărescu, Familia Hetei; efecte la receptare: „familiaritate, bucurie împărtășită sau o tradiție transmisă «din tată în fiu»”, p. 136); nume care trimit la simboluri culturale, mitologice: Drăgaica Roșie, Rusalca Albă, cu diverse efecte pragmatice: funcție incantatorie (Balada, Menestrel), funcție magică (Miracol, Misterium); nume ce evocă simboluri religioase: Vin bisericesc, Vin liturgic, 7 Păcate etc.; nume care conțin apelativul castel [+ aristocrație $]+$ Determinant: Castel Huniade, Castel Jidvei; denumiri care păstrează „reminiscențe nobiliare, fie sub forma unor demnități, fie a unor ritualuri care țin de eticheta impusă de rang” (p. 141): Noblesse, Vinul Cavalerului, Wine Princess etc.

În ce privește numele soiurilor de struguri românești, autoarea vorbește despre $\mathrm{o}$ „motivare semantică în raport cu referentul” (p. 142), avînd la bază o metonimie sau o metaforă. Clasificarea acestora s-a făcut în funcție de: culoare (Negru vîrtos); forma strugurelui (Grasă de Cotnari / Românească); eponim sau etnonim (Nausica, Nicorești); denumiri sinestezice („structuri cumulative care activează simultaneitatea mai multor simțuri prin evocarea unor sugestii vizuale, auditive, olfacto-gustative, ce își «răspund»" (p. 144) (Tămîioasă (Românească)); simboluri zoomorfe, avimorfe (Cocoş, Sìnge de Taur); dimensiune-recipient, dimensiune-cultură viticolă (Babanu, Miniaturi); denumiri circadiene (care surprind parcursul existențial de la vlăstar - strugure copt - vin) (Mugur de viță, Floare de Toamnă); efecte produse (terapeutice, afrodisiace, euforice) (Black Doktor, Erotikon); cuvinte și construcții lingvistice savante (Nec plus ultra, Proles Pontica); mărci „universitare" (Colocviu).

Ca o tendință generală, observă Mihaela Munteanu Siserman, numele vinurilor și ale soiurilor de struguri românești din inventarul cercetat fac trimitere-prin închiderea în structura lor lingvistică-la o imagine (reală sau fictivă, antropomorfă sau toponimă) puternic autohtonizată, care șia cîștigat prestigiul de a funcționa ca marcă (brand) pentru produsul viticol pe care îl reprezintă (și cu care se identifică). 
În ce privește Onomastica senzorialului vizual, autoarea ia în discuție nume de emisiuni din spațiul media românesc (p. 151-175). Abordarea nu este una reducționistă, structurile designative find discutate nu doar sub aspect onomastic, ci dintr-o perspectivă ce extinde analiza înspre semantică și pragmatică. Pornind de la dihotomiapreluată din bibliografia de coloratură francezăpaleo-/neoteleviziune, demersul colegei noastreunul integrativ—taxonomizează emisiunile difuzate pe posturile $t v$ (naționale și comerciale) în funcție de criteriul tematic în:

- emisiuni informative, ale căror titluri se organizează, în general, în jurul substantivului știri (news), ante- sau postpus numelui postului respectiv (România TV News, Stirile ProTV);

- emisiuni economice: se fac observații referitoare la modul în care mutația de paradigmă din sistemul economic românesc al ultimilor 25 de ani are consecințe și la nivelul denumirilor din media video cu profil economic; altfel spus, tendința de occidentalizare economică este redată și la nivelul numelor de emisiuni, care fie păstrează tale-quale un anglicism (Money News), fie asociază într-o sintagmă un cuvînt românesc cu unul străin (internaționalizat): Ora de business;

- în intervalul grafic rezervat numelor de emisiuni meteo, este atinsă și problema necesității racordării omului contemporan la previziunile temporale în funcție de care își planifică o serie de comportamente (vestimentar, de organizare a vacanţelor etc.);

- privitor la numele de emisiuni consacrate revistei presei, autoarea depășește în analiză simpla destructurare lingvistico-onomastică, formulînd observații referitoare la strînsa legătură dintre realizatorii acestora și facțiunea politică simpatizată, concomitent cu exprimarea verbală (limbaj injurios, atacuri la persoană etc.) a dezacordului față de cei situați în partea opusă a eșichierului politic;

- în structura lexico-semantică a numelor de emisiuni documentare (istorice, culturale, artistice, de științe ale naturii, juridice, economice etc.) se regăsesc termeni care trimit explicit (cel mai adesea) la specificul temei tratate: Digicult, România turistică, Tele Arte etc.;

- unitățile / sintagmele designative care constituie titlurile emisiunilor de tip talk-show sau reality- show reconstituie referința directă, prin evocarea reperului temporal (Sinteza zilei, 24 intr-o oră) sau evocă funcția pe care media ar trebui să o aibă referitor la evenimentele prezentate (Imparțial, Vorbeşte liber!-aluzie la „atitudinea nedisimulată pe care analistul prezent în platou trebuie să o adopte față de evenimentul comentat / analizat", p. 165).

Ne-au reținut atenția, în mod deosebit, grație preciziei și minuțiozității interpretării, cele două izotopii pe care autoarea consolidează structura designativă a numelui unui reality-show de succes, și anume Big Brother. În prima dintre lecturi, fratele cel mare trimite la un „sistem opresiv, totalitarist. Ideea de cameră de supraveghere este întărită și de logoul emisiunii: ochiul care supraveghează și vede tot” (p. 167-168). Întro a doua lectură, familială, autoarea observă "asocierea pe care o are în mentalul colectiv semnificația de fratele cel mare [+ autoritate (prin delegație, mai ales în absența părinților), + experiență în raport cu ceilalți]” (p. 168);

- emisiunile de divertisment din România postdecembristă, după cum bine subliniază Mihaela Munteanu Siserman, sînt „avantajoase (pecuniar) doar ofertantului, nu şi ofertatului (care, consumînd doar ceea ce i se dă, renunță treptat la orice criterii evaluative și sfîrșește în a fi un public «drogat», fără reacție, deoarece i-a fost anesteziat / amputat spiritul critic). Această formă de divertisment reproduce tot mai fidel specificul presei tabloide, jonglînd între sexualitate exacerbată și alcov erotic, între injurios și trivial, între nuntă în mijlocul străzii la orele amiezii și interviu «la cald» cu cea mai recentă victimă violată, realizat de cel mai rapid reporter sosit la domiciliul acesteia" (p. 170);

- onomastica titlurilor de emisiuni de sănătate este construită pe principiul transparenței, deținînd cel puțin un lexem cu semantică medicală: Ce se intîmplă, doctore?, Medici de gardă etc.;

- dintre numele de emisiuni gastronomice asupra cărora s-a oprit autoarea, reținem Tinerețe fără bătrînețe, structură oximoronică, prin alăturarea contrariilor existenței umane, tinerețea vs bătrînețea, care trimite la reconstituirea, prin inferență, a unui tipar sintactic condițional: „Dacă mănînci corect în tinerețe, nu vei avea probleme de sănătate la bătrînețe" (p. 173). 
Numele emisiunilor difuzate de diversele posturi de televiziune (peste 150) fie ajută (prin transparență semantico-structurală) la încadrarea emisiunii în genul proxim, fie, dimpotrivă, îngreunează prelizibilitatea conținutului din pricina estompării semanticii expresiei denominative paratextuale, ștearsă de însăși opacitatea (ambiguitatea) ei (vezi p. 174).

În Considerații privind onomastica numismatică: numele de monede naționale (p. 176-188), autoarea, luînd ca punct de pornire o taxonomie lexicosemantică preexistentă (v. nota de subsol nr. 8, p. 179), clasifică diversele nume de monede / bani naționale/-i după: reiterarea (prin traducere) a numelor respective în diferite limbi (dram, lari etc.); regăsirea în denominație a unei referiri la materialul / aliajul (de metale) din care a fost confecționată moneda (gulden, rupie etc.); semnificația de unitate de măsură / greutate a metalului care a servit drept materie primă pentru monedă (dinar, liră etc.); numele „ilustru” „bătut” pe aversul sau reversul monedei (rege, împărat, conducător, personalitate notorie într-un anumit domeniu al vieții sociale) (bolivar, ludovic, napoleon etc.); referința toponimică (stat, regat, regiune) ștanțată pe monedă (euro, forint, stambol etc.); simbolistica de diferite ordini (religioasă, animalieră etc.) la care trimite apelativul numismatic (escudo, leu, sol etc.).

În maniera „epuizantă” a detaliului interpretativ și cu acribia cercetătorului umanist exemplar cu care ne-a obişnuit, colega noastră constată că opțiunea onomastică pentru diversele monede examinaterod al deciziei comunităților etnice sau a suveranului în timpul căruia a fost bătută - trimite la o semnificație puternic înscrisă în codul lingvistic „național”.

Extincțiile onomastice pînă în nomenclatorul medical (Aspecte lingvistice în onomastica medicală, p. 189-204) trădează preocuparea cercetătoarei de a aplica perspectiva filologică și de a se folosi de mijloacele analizei lingvistice şi în cazul limbajelor de specialitate (i.e., discursul medical), în ciuda specificităților multiple, cu funcții diverse la toate nivelurile limbii.

Intersectînd domeniul medical cu cel lingvistic, Mihaela Munteanu Siserman propune o abordare interdisciplinară a numelor de maladii, sindroame și virusuri.

Structurile denominative designative ale claselor semantice identificate au următoarea distribuție constitutivă:
- rădăcină lexicală de sorginte științifică (latinească sau grecească $)+$ substantiv (< derivare sufixală / sufixoidală, generatoare de semnificație): -ree („eliminare, scurgere”(: bronhoree; -ism („stare bolnăvicioasă permanentă”): mongoloism (vezi p. 194);

- Determinat + antroponim / toponim (descoperitorul maladiei / locul de incidență a bolii): maladia Charcot-Marie;

- antroponimul poate trimite la un referent „ilustru”: complexul (lui) OEdip, sindromul Stendhal, sindromul "Alice in Țara Minunilor";

- tropi identificați în structura lingvistică: metonimia [antroponimul substituie numele bolii / sindromului respectiv (Parkinson-ul)] și sinonimia [există opțiuni stilistice în funcție de registrele limbii: locutorul alege una dintre variantele seriilor sinonimice constituite, plecînd de la denumirea standard a bolii / sindromului (boala Biermer $\approx$ anemie pernicioasă)];

- Determinat + toponim (= zona de incidență a virusului / maladiei): sindromul Stockholm, sindromul Ierusalim;

- etnonime (trimitere la numele unui popor): gripa spaniolă;

- „cromonime” (trimitere la o culoare identificată în semiologia medicală): boala limbii albastre, febragalbenă;

- „bestiar” medical (analogii animaliere, unele metaforizante, în morfopatologia bolnavului): boala vacii nebune, gripa aviară, gripa porcină;

- nume „exotice”, pitorești: boala mîinilor murdare ( $\approx$ hepatita A), sindromul copilului zgîlțîit $(\approx$ sindromul Silverman);

- sigle, abrevieri, acronime: CT, RMN, EKG.

Colega noastră reunește într-o formulă foarte reușită austeritatea științifică a denominațiilor investigatespecifică domeniului medical—cu pitorescul aceleiași terminologii „traduse” „pe înțelesul tuturor” (pacienților). Altfel spus, limbajului de strictă specialitate i se administrează o „transfuzie” de popularizare, în urma căreia acesta se „tranzitivizează”, permițînd dezlegarea „poveștii” (referința antroponimică / toponimică reală) dindărătul unui complex sonor „condamnat” altfel la ermetism pentru profani.

În demersul său științific, autoarea s-a oprit și asupra colocațiilor, paremiilor, expresiilor din frazeologia românească (Repere onomastice în structuri fixe românești. Perspective sociolingvistice și culturale, 
p. 206-224), în al căror nucleu semantic se poate recunoaște „urma” unui nume propriu.

Într-o pertinentă abordare de factură stilisticofuncțională și culturală, Mihaela Munteanu Siserman semnalează motivarea structurilor onomastice identificate, în sensul descoperirii existenței unei relații între referințele nominatoare și un eveniment factual asumat de către o anume comunitate etnolingvistică. Totodată, autoarea remarcă funcția evocatoare cu care sînt „încărcate” structurile respective, precum și diferitele efecte de sens degajate: ambiguizare deliberată, persiflare, ironie etc.

Structura de suprafață înlesnește clasificarea expresiilor fixe în funcție de categoria onomastică din care face parte numele propriu conţinut: antroponime (a fide pe vremea lui Pazvante Chioru'; e țara lui papură Vodă; a fi Cănuță om sucit); etnonime (a lua luleaua neamțtului „a se îmbăta”); personaje biblice și sărbători religioase (construite cel mai adesea în jurul denominaţiilor Creatorului, ale Sărbătorilor de Paști și de Crăciun: Domnu' a dat, Domnu'a luat; la Paștile cailor; Crăciunul al sătulului și Paștele al fudulului); toponime (a nimeri ca orbul în Brăila); nume de culori (a fi / deveni negru de supărare; a fi / a se face alb ca varul). În cadrul cromonimelor, dintre interpretările pe care autoarea le aplică respectivelor structuri, o reținem pe cea referitoare la expresia $a$ aduna bani albi pentru zile negre: „Spaima «zilei de mîine» și a neputinței de a-și asigura existența este «mîntuită» prin reflexul omului chibzuit de a economisi bani în vremuri «albe» pentru situaţii cu care se poate confrunta la un moment al vieții (imposibilitate fizică, financiară sau de altă natură a «zilelor negre» ); în plan frazeologic, situația este redată prin invocarea unei structuri care face evidentă opoziția cromatică alb / negru: a strînge bani albi pentru zile negre. Prin antifrază, expresia «răsturnată» creează efecte de sens contrare înțelesului originar: Unii strîng bani albi pentru zile negre, iar alții strîng bani negri pentru zile și nopți albe” (p. 220).

Prin comentarii detaliate, Mihaela Munteanu Siserman ne invită și, totodată, ne ghidează înțelegerea prin chei de lectură conotative, singurele apte să recupereze-metaforic-sensul denotativ al structurilor explorate.

Periplul onomastic al autoarei se încheie printro analiză structurală și semantică a supranumelor cu care au rămas în istorie conducătorii Evului Mediu românesc (din Ţara Românească și Moldova) (Supra- nume ale conducătorilor (voievozilor, domnitorilor) din Evul Mediu românesc, p. 226-246).

Înscriindu-se pe linia exegetică de profil, Mihaela Munteanu Siserman remarcă rolul individualizator şi diferenţiator al supranumelui în general, atribuitorul acestuia situîndu-se fie în aceeași tabără cu suveranul, fie în cea adversă.

Înainte de a glosa formulele antroponimice considerate, autoarea se oprește asupra termenilor generici care preced sau urmează (în diferite roluri tematice) supranumele / prenumele / numele (sau doar două dintre acestea combinate) personajului istoric respectiv. Este vorba despre apelativele domn, domnitor, vodă, voievod, cărora le este consacrat un bine-venit studiu lexicografic.

Fiecare dintre categoriile semantice de supranume identificate este ilustrată, mai întîi, prin avansarea cîte unui exemplu (nominal) din alte spații istorice şi culturale decît cel anunțat drept areal de cercetare pentru obiectul propus. Prin aceasta, cititorul poate observa cu ușurință similitudinile dintre sistemele denominatoare ale civilizațiilor etnolingvistice diferite, consecință a unor mentalități și cutume asemănătoare în planul comportamentului psihosocial. Astfel, studiul colegei noastre depășește granițele metodologiilor de la care se revendică, în general, o abordare filologică, tinzînd spre o perspectivă integratoare (a localului în universal), în care istoria și legenda (folclorul) coexistă cu studiul faptului de limbă concret, investigat lexicografic, structural şi semantic pînă la ultima potență semnifica(n)tă. Cumva, studiul de față are profilul unui curs de istorie reconstituită prin „povestea” din spatele supranumelor; pornind de la considerarea acestora, cititorul ajunge de fiecare dată in medias rerum, istoria nominală trimiţînd la contextul factual complementar.

În funcție de modul în care circumstanțele (referințele extralingvistice) au fost evaluate / valorizate de către contemporani sau posteritate (unele supranume au fost conferite în timpul vieții, altele post mortem), autoarea împarte corpusul onomastic în două categorii: supranume cu o conotație pozitivă vs supranume cu o conotație negativă. Folosindu-se de criteriile semantico-stilistic și pragmatic, Mihaela Munteanu Siserman face "portretul-robot” al conducătorului vizat, evocînd evenimentul notoriu care l-a „sudat” indestructibil de supranume.

Din clasa supranumelor pozitive enumerăm: 
Basarab I Intemeietorul, Bogdan I Descălecătorul [personalități al căror (supra)nume este asociat cu / „traduce” întemeierea / înființarea unei "țări” (punerea de hotar și lege într-un ținut românesc)]. Alte supranume sînt transparente la nivelul unui calificativ etnic (aluzie la originea maternă, cel mai adesea): Iancu Sasul, Vasile Lupu Albanezul, Petru Cazacul / Polonul, Alexandru Stolnic Românul. Alteori, supranumele „consemnează” caracterul bun, înțelept, viteaz al conducătorului: Alexandru cel Bun, Mihai Viteazul. Supranumele funcționează și ca operator de diferențiere în ce privește succesiunea la tron a celor care purtau acelaşi prenume („omonimie antroponimică"), autoarea notînd că practica „numerotării” nu caracterizează specificul tradiției noastre (față de Franța, Anglia, unde succesiunea la tron era condiționată de apartenența dinastică): Petru cel Tînăr, Vlad cel Tînăr, Mircea cel Bătrîn etc. Supranumele poate actualiza și o izotopie a religiosului, conotată pozitiv (Ștefan cel Mare și Sfint, Radu Paisie) sau negativ [de trădare a religiei originare și de „vindere” la mahomedanism (Mibnea Turcitul)]. Şi îndeletnicirile practicate mai înainte de învestitură sînt cuprinse în structura lexicosemantică a supranumelor unora dintre domnitori: Vlad Călugărul, Mircea Ciobanul etc. Frumusețea exterioară, preocuparea pentru zădărniciile lumești, galanteria sînt, de asemenea, „înregistrate” în codul nominal neconvențional: Radu cel Frumos, Petru Cercel. Aplecarea spre anumite patimi culinare devine marcă distinctivă denominativă: Mămăligă Vodă, Mălai-Vodă.

Supranumele cu conotaţie negativă se referă la un caracter moral deficitar, prin exagerare, uneoridizarmonie în alcătuirea fizică sau sînt legate de felul în care referentul a gestionat o situație de criză climaterică ce a avut loc în perioada domniei lui, toate fiind construite în jurul semelor [+ tiranie]: Ștefan cel Crud, Aron Vodă cel Cumplit (Tiranul), Mihnea cel Rău, Vlad Țepeș; [+ infirmitate fizică]: Ștefan Surdul, Petru S,chiopul, Negru-Vodă; [+ calamități naturale]: S,tefan Lăcustă, Papură-Vodă etc.

Cartea aici recenzată reprezintă un punct de referință în bibliografia de specialitate onomastică, dar nu numai, combinarea metodologiilor din domenii aflate nu întotdeauna într-o explicită complementaritate îndreptățind-o să constituie un reper în exegeza filologică românească.

Bună cunoscătoare a limbii franceze, cu dovedit talent de interpret idiomatic (vezi traducerile efectuate de autoare), Mihaela Munteanu Siserman aplică teoriile moderne centrate pe referința nominală (subiectul tezei de doctorat) asupra nomenclatorului (antroponimic, toponimic etc.) din ultima sa carte.

Găsim admirabilă și deloc la îndemîna oricui dibăcia cu care reușește să orchestreze-sub „baghetă” onomastică_, „ritmuri” eliberate de instrument(ar)e diferite. Deținînd informații din domeniul lexicologiei, ea le corelează fructuos, neratînd spectacolul „des-compunerii” fiecărei denominații analizate în „constituenții imediați” sau mai îndepărtați. Altfel spus, autoarea este adepta unei tehnici de cercetare integrale, care depășește de fiecare dată abordările mono-, bi- sau tridisciplinare anunțate între perspectivele teoretice avansate, trecind dincolo de acestea şi oferind o interpretare pluriperspectivistă: de la schema lexico-gramaticală a cuvîntului-nume, prin sens (discurs), pînă la recuperarea referinței (denotatului). $\mathrm{Cu}$ alte cuvinte, Mihaela Munteanu Siserman reconstituie, în întreprinderile sale-printr-o eficientă coabitare (și corespundere) a preceptelor de varii proveniențe metodologice-istoria cînd obiectivă, cînd subiectivă a „vieții lumii” numelor. 